\title{
KEBERADAAN BAHASA REJANG PESISIR KABUPATEN BENGKULU UTARA DITINJAU DARI SEGI KESANTUNAN BAHASANYA
}

\author{
Titje Puji Lestari \\ Universitas Dehasen Bengkulu
}

\begin{abstract}
Abstrak
Keberadaan Bahasa Rejang Pesisir Kabupaten Bengkulu Utara ditinjau dari segi kesantunan bahasanya bertujuan untuk mendeskripsikan cara pengungkapan tuturan atau kesantunan pada masyarakat Rejang Pesisir dan juga bertujuan untuk mendeskripsikan sifat-sifat tuturan pada masyarakat Rejang Pesisir. Metode penelitian yang digunakan adalah metode deskriptif kualitatif.Teknik pengumpulan data dilakukan dengan teknik (1) observasi, (2) perekaman, (3) pencatatan, (4) wawancara. Langkah-langkah penelitian: (1) mencari data dengan perekaman, (2) transkripsi data,(3) menerjemah data, (4) pengkodean data, (5) pengklasifikasian data, (6) analisis data, (7) penyimpulan hasil penelitian. Dari hasil penelitian ini ditemukan bahwa percakapan atau tuturan bahasanya berdasarkan teori Leech.
\end{abstract}

Kata kunci : Kesantunan, Bahasa Rejang

\begin{abstract}
The existence of Coastal Rejang Languages in North Bengkulu Regency in terms of politeness of the language aims to describe the way of expressing speech or politeness in the Coastal Rejang community and also aims to describe the properties of speech in Coastal Rejang community. The research method used was a descriptive qualitative method. Data collection techniques were carried out using (1) observation, (2) recording, (3) note taking, (4) interviewing. Research steps: (1) searching data by recording, (2) data transcription, (3) translating data, (4) data encoding, (5) data classification, (6) data analysis, (7) summarizing research results. From the results of this study it was found that the language conversation or speech is based on Leech's theory.
\end{abstract}

Keywords: Politeness, Rejang Language

\section{PENDAHULUAN}

Bahasa Rejang adalah suatu alat komunikasi masyarakat Rejang dalam menyampikan maksud dan tujuan baik secara lisan maupun tulisan. Bahasa rejang adalah bahasa yang dipergunakan masyarakat Rejang Lebong sebagai bahasa lisan untuk menyampaikan maksud dan tujuan di rumah maupun di luar rumah dan dalam pergaulan sehari hari. Peranan bahasa rejang menunjukkan keberadaanya ditengah-tengah masyarakat, di sekolah, upacara adat dan upacara keagamaaan.

Bahasa rejang telah menjadi bahasa pengantar yang tidak akan dilupakan masyarakat rejang baik di kampong halaman maupun di perantauan.Suku Rejang adalah salah satu suku tertua di Sumatera dan merupakan suku yang mendominasi di Provinsi Bengkulu. Nah suku Rejang ini kebagi lagi jadi 3 yaitu Rejang Kepahiang, Rejang Curup, dan Rejang Lebong. Pembagian Suku ini berdasarkan karena dialek(logat) bahasa yang berbeda. Secara filosofis, perbedaan dialek bahasa Rejang terjadi karena faktor jarak, faktor sosial, dan faktor psikologis dari suku Rejang itu sendiri. Menurut teman-teman yang sudah pernah mendengar saya menggunakan bahasa Rejang, ada yang bilang kalau bahasanya mirip kayak bahasa cina, aah masa. Dan kebanyakan mereka juga baru mendengarkan bahasa Rejang, ya tentu saja apalagi daerah jakarta yang sering didengar adalah bahasa betawi,sunda,jawa kali yaaa ,heee. Dengan keadaan seperti ini, berbangga hati juga karena menjadi orang yang memperkenalkan bahasa Rejang kepada mereka. Bahasa Rejang juga 
mempunyai tulisan mereka sendiri yaitu huruf "Kaganga" banyak generasi penerus saat ini tidak tahu bahkan tidak pernah melihat dan belajar bahasa kaganga ini. Seharusnya bahasa kaganga tetap ada supaya huruf kaganga itu tidak mati dan hilang dimakan zaman

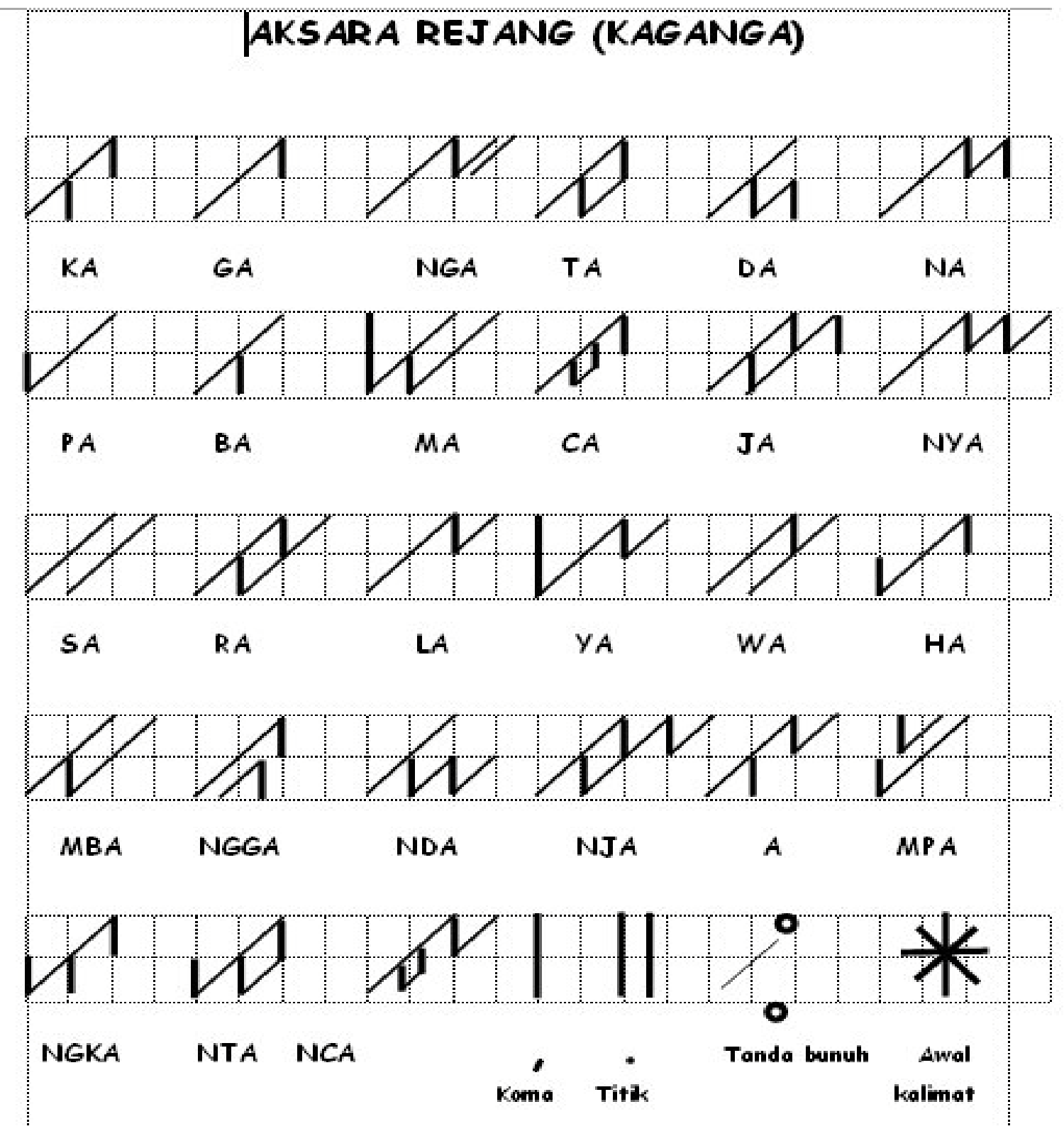

Gambar diatas adalah huruf kaganga. Bahasa Rejang memiliki variasi ataupun perbedaan menurut dialek yang dimiliki berdasarkan tiga kelompok dialek Rejang. Di bawah ini adalah beberapa kosakata dalam bahasa Rejang yang memiliki perbedaan antar kelompok dialek Rejang.

\begin{tabular}{|l|l|l|l|}
\hline \multicolumn{1}{|c|}{ Bahasa Indonesia } & Dialek Lebong & Dialek Curup & Dialek Kepahiang \\
\hline Kamu & Ko & Ko & Ko \\
\hline
\end{tabular}




\begin{tabular}{|c|c|c|c|}
\hline aku, saya & Uku & Uku & Uku \\
\hline Mau & Lok & Lak & Lak \\
\hline Makan & muk mei & muk mie & muk mea \\
\hline lauk untuk penyerta nasi & Lapen & Lapen & gulea \\
\hline menikah & Betunok & betunak & betunak \\
\hline Siapa & Api & api & Api \\
\hline Nama & Gen & gen & Gen \\
\hline Jangan & Jibeak & ji’beak & Jikba \\
\hline menabrak & Numua & menumua & menumur \\
\hline Darat & da'et & da'et & dahet \\
\hline Air & Bioa & bioa & Bioa \\
\hline Sedikit & Didik & didik & didik \\
\hline Banyak & Dau & deu & Deu \\
\hline Cucu & Kpau & peu & Kpeu \\
\hline Pergi & Alau & aleu & Aleu \\
\hline makanan rebung khas rejang & Lemea & lema & Lema \\
\hline dodol kelapa & Pujuak & pojoak & glamai \\
\hline kampung & Sadei & sadie & sadea \\
\hline Marah & Mengiak & mengiak & mengeah \\
\hline Nanti & $\mathrm{Be}$ & $\mathrm{Be}$ & $\mathrm{Be}$ \\
\hline sekarang, kini & Uyo & uyo & Uyo \\
\hline Turun & tu'un & tu'un & tuhun \\
\hline Anak & Anok & anak & Anak \\
\hline Cicit & Piut & piut & Piut \\
\hline moyang & Puyang & puyang & puyang \\
\hline Ada & Ade & ade & Ade \\
\hline Depan & Adep & adep & Adep \\
\hline
\end{tabular}




\begin{tabular}{|c|c|c|c|}
\hline Sendiri & su'ang & su'ang & suhang \\
\hline Sarung & so'ong & so'ong & sohong \\
\hline Besok & Memen & memen & memen \\
\hline Malam & Kelmen & kelmen & kelmen \\
\hline Pagi & Kabuki & kabuk & kabuk \\
\hline Tadi & Nano & nano & Nano \\
\hline Arti & Tai & Tei & Tei \\
\hline Telur & Tenoa & tenoa & tenoa \\
\hline Anjing & Kuyuk & kuyuk & kuyuk \\
\hline Susah & Saro & saro & Saro \\
\hline Tahu & Namen & namen & namen \\
\hline Tahun & Taun & taun & Taun \\
\hline sabut kelapa & Sobot & sobot & sobot \\
\hline Kelapa & Nioa & nioa & Nioa \\
\hline Kepala & Ulau & uleu & Uleu \\
\hline Badan & Awok & awak & awak \\
\hline Kaki & Kekea & kekea & kekea \\
\hline Tangan & Tangen & tangen & tangen \\
\hline Jari & ji’ai & ji’ei & Jihei \\
\hline Jempol & bei tangen & bie tangen & bea tangen \\
\hline tunjuk/jari telujuk & Tunyuk & tunyuk & tunyuk \\
\hline jari tengah & ji’ai donok & ji’ei donok & jihei tengeah \\
\hline jari manis & ji’ai manis & ji’ei manis & jihei manis \\
\hline Kelingking & anok inik/inik & anak inik/inik & kliking \\
\hline induk jari kaki & bei kekea & bie kekea & bea kekea \\
\hline pusat/pusar & Posok & posok & posok \\
\hline Pelacur & Gudua & gudua & gudua \\
\hline
\end{tabular}




\begin{tabular}{|l|l|l|l|}
\hline Mata & Matai & matei & matei \\
\hline Hidung & Yung & yung & Yung \\
\hline Gigi & Epen & epen & Epen \\
\hline Telinga & ti'uk & ti'uk & tihuk \\
\hline Punggung & Kedong & kedong & kedong \\
\hline Leher & ka'gen & ka'gen & kahgen \\
\hline Kuduk & Tukuk & tukuk & tukuk \\
\hline Lutut & ulau ketot & uleu ketot & uleu ketot \\
\hline Kuku & Selon & selon & Slon \\
\hline Rambut & Buk & buk & Buk \\
\hline siku tangan & Sekoa & sekoa & sekoa \\
\hline Bahu & ba'au & ba'eu & baheu \\
\hline Bibir & Bibia & bebea & bibih \\
\hline Dating & Teko & teko & Teko \\
\hline Naik & Bekenek & bekenek & bekenek \\
\hline Pulang & belek & belek \\
\hline
\end{tabular}

Dari pemaparan di atasAda satu dialek rejang yang terlupakan atau belum di bahas yaitu dialek rejang pesisir yang mana terdapat di Bengkulu utara dan Bengkulu tengah. Pada dialek rejang pesisir di Bengkulu utara dialeknya berbeda dengan 3 dialek rejang yang sudah dibahas di atas tadi. Dengan permasalahan ini, maka penulis mengangkat judul "Keberadaan Bahasa Rejang Pesisir Bengkulu Utara yang Ditinjau Dari Kesantunan Bahasanya”.

Konsep utama dalam pragmatik linguistik adalah sopan santun. Telah dikemukakan (misalnya, Robin Lakoff, Brown dan Levinson, dan Leech) bahwa sopan santun merupakan tingkat interaksi pertuturan di samping kaidah kooperatif. Robin Lakoff melihat kaidah Grice sebagai kaidah penjelas dan mengusulkan bahwa terdapat dua kaidah awal "Kompetensi Pragmatik”. Yaitu “Buatlah perkataan anda jelas” dan "Sopanlah”. Lakoff (dalam Chaer 2010:46) menyatakan bahwa jika tuturan kita ingin terdengar santun ditelinga pendengar atau lawan tutur harus memenuhi tiga kaidah, yaitu formalitas, ketidaktegasan, dan persamaan atau kesekawanan. Formalitas ialah jangan memaksa atau angkuh, ketidaktegasan berarti buatlah sedemikian rupa agar lawan tutur dapat 
menentukan pilihan dan yang ketiga yaitu kesekawanan berarti bertindaklah seolah-olahnya sama dengan mitra tutur. Fraser (dalam Chaer 2010:47) menyatakan bahwa kesantunan adalah properti yang menurut lawan tutur adalah bahwa si penutur tidak melampaui hak-haknya dan kewajibannya. Fraser membedakan antara kesantunan dan penghormatan, suatu penghormatan adalah suatu perilsaya hormat terhadap seseorang atau sebagai simbolis untuk menyatakan penghargaan secara reguler. Seseorang yang berperilaku hormat terhadap orang lain, belum berarti seseorang tersebut berperilaku santun karena kesantunan adalah masalah lain.

Berdasarkan pengertian kesantunan oleh Fraser tersebut, Gunawan (dalam Chaer 2010:47) menyatakan bahwa ada tiga hal yang perlu diulas mengenai kesantunan. Yang pertama kesantunan merupakan suatu properti atau bagian dari kesantunan, jadi bukan tuturan itu sendiri. Kedua, pendapat pendengarlah yang menentukan dalam suatu tuturan. Dan ketiga, kesantunan tersebut dikaitkan dengan hak dan kewajiban. Artinya, apakah sebuah tuturan terdengar santun atau tidak diukur berdasarkan apakah si penutur tidak melampaui haknya terhadap lawan tutur dan apakah si penutur memenuhi kewajibannya kepada lawan tuturnya. Berdasarkan pengertian diatas, hak yang dimaksud ialah sesuatu yang menjadi milik penutur atau lawan tutur dan yang dimaksud dengan kewajiban adalah keharusan yang harus dilakukan oleh pertuturan. Seperti bertanya merupakan hak yang dimiliki oleh penutur kepada lawan tutur. Dan sebagai lawan tutur memiliki kewajiban untuk menjawab pertanyaan tersebut dan juga memiliki hak untuk tidak menjawab.

\section{METODE PENELITIAN}

Metode Penelitian Metode penelitian yang digunakan dalam penelitian ini adalah metode deskriptif kualitatif. Metode deskriptif ialah suatu cara untuk memperoleh data yang bersifat fakta dan empiris. Seperti yang dikemukakan oleh Sudaryanto (1988:62) bahwa penelitian deskriptif adalah penelitian yang dilakukan sematamata berdasarkan pada fakta yang ada atau fenomena yang empiris yang hidup di dalam penutur-penuturnya, sehingga yang dihasilkan atau dicatat berupa perian bahasa yang biasa dikatakan sifatnya seperti potret: uraian seperti adanya. Metode ini dimanfaatkan untuk memperoleh data secara lengkap dan objektif secara apa adanya. Menurut Djajasudarma (1993:15) menyebutkan data deskriptif bukanlah berupa angka-angka, dapat berupa kata-kata atau gambaran sesuatu. Sehubungan dengan penjelasan metode deskriptif tersebut, peneliti ingin melakukan penelitian dengan memperoleh data yang fakta dan empiris seperti apa adanya dan mendeskripsikan atau memberikan gambaran atas permasalahan tentang kesantunan dalam berbahasa rejang dalam penelitian dalam masyarakat Rejang Pesisir Bengkulu Utara.

Teknik pengumpulan data yang telah dilakukan yaitu: 1. Observasi. Observasi dilakukan dengan mengamati kejadian atau tingkah laku yang digambarkan akan terjadi. Mencatat data observasi dengan pertimbangan dan penilaian terlebih dahulu, 2. Wawancara. Wawancara dalam 
tahap ini penyediaan data dilakukan dengan cara peneliti melakukan percakapan atau kontak dengan penutur selaku narasumber (Mahsun, 2011: 250), 3. Rekaman. Rekaman digunakan sebagai bukti autentik dalam penelitian. Dalam rekaman terdapat suara yang nantinya dapat digunakan peneliti sebagai bahan penelitian pada proses analisis data, antara lain transkip, identifikasi, dan klasifikasi data, 4. Teknik catat. Teknik ini dilakukan dalam menulis temuan-temuan di lapangan dalam sebuah buku. Dalam melakukan pencatatan di lapangan, peneliti mendeskripsikan segala sesuatu. Teknik analisis data dalam penelitian ini yaitu 1. Transkip data, hasil tuturan dalam interasi bahasa rejang sehingga bahasanya dapat diartikan menjadi bahasa indonesia yang benar dan dimengerti oleh pembacanya, 2. Analisis transkrip data 3. Pengelompokan, 4. Hasil analisis data , 5. Keabsahan hasil analisis data.

\section{HASIL PENELITIAN DAN PEMBAHASAN}

1. Maksim kebijaksanaan

Ahmad Thamrin : singgeak,... (singgah/ mampir)

Rama : awu wan,. (iya, om)

Ahmad thamrin : maroba ngupi kileak ade pisang nebus yo. (sini, kita minum kopi dulu dan ada pisang rebus)

Tuturan di atas adanya maksim kebijaksanaan dimana yang lebih tua menawarkan makanan dan minuman kepada anak muda yang sedang lewat di depan rumahnya.

2. Maksim kedermawanan

Sarini : aroba suak, ite mukmei nak café o’ (ayo dek kita makan di kafe itu)

Tari : uku coa gen taci nga ( aku tidak ada uang kak)

Sarini : uku gi traktir, pas kulo uku pei gajian ( aku yang bayarkan karena aku baru saja gajian)

Sarini : *senum sumbringah*

Dari tuturan diatas tampak jelas kedermawanan seseorang untuk mengajak temannya yang usianya di bawah dia untuk makan di tempat makan.

3. Maksim penghargaan

Selo : maaaakkkkkkkk!!!!!!!!!!!!!! Sambil berlari (ibu......)

Mak : getai ko yo ? (ada apa dengan kamu)

Selo : uku dapet reking do mak nak kelas (aku dapat juara 1 di kelas)

Mak : au jano?, cubo uku kembliek ( iya? Coba sini ibu lihat)

Selo : *memperlihatkan rapotnya*

Mak : au gi, amen awei o men ite jalan jalan au nak mai kulau ( iya, kalau begitu besok kita jalan jalan ke Bengkulu)

Dari tuturan di atas adanya penghargaan yang diberikan oleh ibu kepada anaknya yang sudah berprestasi. 
4. Maksim kesederhanaan

Pak kades : : kundei ipe udi sanak ? (dari mana kalian saudara ku)

Warga : kundei saweak suak ( dari sawah saudaraku)

Pak kades : maroba singgeak mai umeak keme, kalau kalau ade gin am nembuk ne.... (sini mampir dulu siapa tau ada makanan yang bias dimakan)

Warga $\quad$ : awu, mokasiak, keme lajau bae bi lak megrib (iya, terimakasih tapi kami pulang saja karena hari sudah mau magrib)

Tuturan di atas tampak adanya kesederhanaan pak kades aur gading untuk bertegu sapa dengan warganya dan menawarkan untuk singgah dan makan di rumahnya itu bentuk kesederhanaan juga, tidak tampak kesombongan pada tuturan tersebut.

5. Maksim permufakatan

Ibu rini: nukua gi luyen bae nak,. ( beli yang lain saja, nak)

Anak : coa la kuku lak gi dio mak *menunjukan baju bagus berwarna pink atau merah muda

Ibu Rini $\quad$ :coa cukup taci ne nak ( tidak cukup uangnya)

Anak : au ba ne gi doo bae, gi warno putiak (iyalah memilih mengalah dengan mengambil baju berwarna putih )

Ibu Rini $\quad$ : au, mak ba (iya, ambillah)

Dari tuturan tersebut adanya kesepakatan antara ibu dan anak yang menyetujui membeli baju yang lebih murah karena uang yang tidak cukup. Dan anaknya pun menyetujui walau dengan berat hati.

6. Maksim kesimpatian
Helty $\quad$ : uku permisi belek kileak au (saya permisi pulang ya)
Mar : getai ti?
Helty : : indok ku ningga (ibuku meninggal)
Mar $\quad$ : au au, sabar au tuk..... ( iya, iya.. sabar ya keponakan)

Tuturan di atas terlihat rasa simpati atas meninggalnya orang tua dari helty yang terlihat sedih.

\section{SIMPULAN}

Dari hasil analisis tuturan kesantunan dalam berbahasa ditemukan beberapa maksim yang menyatakan tuturan itu tergolong dalam masing-masing maksimnya. Untuk itu setiap bertutur dengan bahasa baik itu bahasa rejang ataupun bahasa lain kita hendaknya melihat siapa yang diajak bicara dan lingkungannya serta situasi pada saat tuturan berlangsung. Dari hasil analisis juga kita dapat membedakab keenam maksim menurut Leech yaitu ada maksim kebijaksanaan, kedermawanan, penghargaan, kesederhanaan, pemufakatan, dan kesimpatikan. Bahasa rejang pesisir berbeda dengan bahasa rejang lebong, curup, ataupun kepahyang untuk itu saya sebagai penulis merasa penting untuk meneliti bahasa rejang pesisir khususnya daerah Bengkulu utara desa 
Aur Gading agar dapat diketahui oleh orang lain bagaimana bahasanya. Untuk lebih lanjut agar ada penelitian lebih dalam mengenai bahasa daerah rejang ini.

\section{DAFTAR PUSTAKA}

Chaer, Abdul. (2010). KesantunanBerbahasa. Jakarta: Rineka Cipta.

http//bahasarejangkagangabengkuluutara.diaksespadatanggal09oktober2019.pukul21.00wib.

Kridalaksana, Harimurti. (1985). Fungsi Bahasa Dan Sikap Bahasa. Flores: Nusa Indah.

Rahardi, Kunjana. (2003). Berkenalan Dengan Ilmu Bahasa Pragmatik. Malang: DIOMA

Sudaryanto. (1993). Metode dan Aneka Teknik Analisis Bahasa. Yogyakarta: Duta Wacana University Press.

Sugiyono. (2006). Metode Penelitian Pendidikan. Bandung: Alfabeta

Sukardi. (2003). Metodologi Penelitian Pendidikan. Jakarta: Bumi Aksara. 